\title{
A case of fulminant liver failure in dengue haemorrhagic fever
}

\author{
SCJ Wijeweera', K Senevirathna ${ }^{2}$, MK Ragunathan ${ }^{3}$ \\ ${ }^{\prime}$ Registrar in Medicine, ${ }^{2}$ Senior Registrar in Medicine, ${ }^{3}$ Consultant Physician, Teaching Hospital, Karapitiya, \\ Galle.
}

e-mail address of the corresponding author, Dr. Sandini Wijeweera: sandinijayasinghe@yahoo.com

\section{Introduction}

Currently, another epidemic of Dengue has emerged in Sri Lanka. Variations from the usual clinical pattern have been observed more frequently in this epidemic including very high transaminase levels in patients with Dengue. However only few cases were reported with acute hepatic failure and encephalopathy occurring in Dengue in adults ${ }^{1,2,3,4,5}$.

\section{Case report}

A28 year-old previously healthy, non-alcoholic male presented to us with a history of fever with chills for three days associated with vomiting and dizziness. He had no bleeding manifestations. On admission, he was plethoric with a temperature of $100 \mathrm{~F}$ and blood pressure of $110 / 70 \mathrm{mmHg}$ without a postural drop. His lungs were clear and the abdomen was soft. The initial full blood count showed a white cell count of $3,200 / \mathrm{mm}^{3}$ (N-43\%, L-55\%, E-2\%), Hb\% of 16.9 $\mathrm{g} / \mathrm{dL}$ with PCV of $48 \%$ and a platelet count of $20,000 / \mathrm{mm}^{3}$. The blood picture was suggestive of dengue fever. On the following day, platelet count dropped to $10,000 / \mathrm{mm}^{3}$ and the PCV rose to $50 \%$. Twelve hours later he became drowsy. He was haemodynamically stable with no evidence of internal haemorrhage and also intracranial haemorrhage was excluded by a normal CT scan. Platelet count was $6,000 / \mathrm{mm}^{3}$ then. By the next day patient's level of consciousness deteriorated further. His Glasgow Coma Scale was 9/15. There were petechial haemorrhages and mild gum bleeding. He was icteric with a tender hepatomegaly and a small amount of abdominal free fluid. His blood pressure was $140 / 90 \mathrm{mmHg}$ with a normal pulse rate and volume. The platelet count was $20,000 / \mathrm{mm}^{3}$ with a PCV of $40 \%$. Blood picture showed no evidence of DIC. Blood urea and serum electrolytes were normal. The liver function tests were deranged:
SGOT - 3,110 U/L and SGPT - $710 \mathrm{U} / \mathrm{L}$, $\mathrm{PT} / \mathrm{INR}$ - 1.5, total serum bilirubin - $120 \mu \mathrm{mol} / \mathrm{L}$ (direct fraction $-77 \mu \mathrm{mol} / \mathrm{L}$ ).

We managed him as acute liver failure with hepatic encephalopathy and started him on standard liver failure regime including syrup lactulose $20 \mathrm{~mL}$ tds, oral metronidazole $400 \mathrm{mg}$ tds, vitamin K $10 \mathrm{mg}$ IV daily and bowel wash daily. At the same time we gave IV fluids to manage DHF and also transfused FFP and platelets. The patient was given ICU care with close monitoring in the critical stage. There were minor bleeding episodes attributed to coagulopathy although the platelet count was more than $20,000 / \mathrm{mm}^{3}$. There was gradual improvement in patient's condition and hence we discharged him after 10 days of hospital stay. On discharge his platelet count was $90,000 / \mathrm{mm}^{3}$ with PCV - 34\%, PT / INR - 1.0, SGOT - $93 \mathrm{U} / \mathrm{L}$ and SGPT - $56 \mathrm{U} / \mathrm{L}$.

Both IgM and $\operatorname{IgG}$ antibodies for dengue were positive, but negative for hepatitis B virus surface antigen and hepatitis A IgM antibodies.

\section{Discussion}

Dengue infections are caused by a flavivirus which has four sero types (DEN1-4). It is the commonest arbovirus and a common cause of haemorrhagic fever in the world. The virus is transmitted by mosquitoes of Aedes genus, mainly Aedes aegypti. The severity of infection varies from mild undifferentiated febrile illness to dengue haemorrhagic fever to dengue shock syndrome.

Dengue virus can infect many cell types in the body to cause diverse clinical effects. Liver involvement appears to occur more commonly with serotypes DEN3 and DEN4 ${ }^{1}$. Although liver is not the main target organ, direct infection of hepatocytes and Kupffer cells by dengue virus can be observed ${ }^{6}$. 
Hepatocellular necrosis in dengue mainly affects the mid-zonal area and sometimes centrilobular region ${ }^{6}$. In fact, dengue viral RNA and protein have been detected from mid-zonal hepatocytes ${ }^{6}$. Liver involvement is due to cytopathic effect by infection of liver cells by the virus per se, rather than a secondary immune reaction. Therefore, liver involvement can be seen both in primary infections ${ }^{7}$ and re-infections.

An increase in liver transaminases is observed in the first week of dengue infection mainly in dengue haemorrhagic fever rather than in dengue fever. This can vary from 2-3 folds to more than 10 fold rise from normal level. SGOT rises more than SGPT which is different from other types of viral hepatitis ${ }^{6}$. This was the pattern observed in our patient as well. He was a non-alcoholic which excluded another common cause of SGOT $>$ SGPT.

Acute liver failure is defined as rapid onset of acute encephalopathy and coagulopathy (INR $\geq 1.5$ ) in the setting of liver failure of $\leq 6$ weeks duration. Even though liver involvement is commonly observed with SGOT rising more than 10 folds of normal value, acute liver failure is not commonly seen in dengue infection as evidenced by extensive studies done locally and abroad ${ }^{8,9}$. In our patient PT / INR was 1.5 initially, which came down later. He was in encephalopathic coma which was evident by low GCS.

Acute hepatic failure due to dengue infection with subsequent complete recovery has been reported in two adult patients from India ${ }^{4,5}$, one from Singapore ${ }^{3}$ and one from USA ${ }^{1}$. A case with fatal outcome was reported in an immigrant to $\mathrm{UK}^{2}$.

In dengue infection liver involvement is not chronic as in hepatitis B or C infection. Transaminase levels drop back to normal in about the third week of illness ${ }^{6}$. Same findings were seen in our patient as liver enzymes dramatically came down with clinical recovery.

Elevation of liver enzymes per se is not a bad prognostic sign in dengue?. With liver involvement the hospital stay will be prolonged with delayed recovery. However, with acute liver failure the mortality rate shoots up which adds to the toll of haemorrhagic phase and shock syndrome ${ }^{6}$. With acute liver failure a patient can develop haemorrhages even with a platelet count of
$>20,000 / \mathrm{mm}^{3}$, as observed in our patient, due to coagulopathy ${ }^{3}$.

Most patients with acute liver failure in dengue infection had hypotension which was not observed in this patient at any time ${ }^{1,2}$. The common causes of acute liver failure in tropics, hepatics A, hepatitis B, overdose of paracetamol and alcohol consumption were excluded in our patient.

\section{References}

1. Gasperino J, et al. Fulminant liver failure secondary to haemorrhagic dengue in an international traveler. Liver Int. 2007 Oct; 27(8): 1148-51.

2. Lawn SD, et al. Dengue haemorrhagic fever with fulminant hepatic failure in an immigrant returning to Bangladesh, Clin Infect Dis, 2003 Jul 1; 37(1): e1-4.

3. Ling LM, et al. Fulminant hepatitis in dengue haemorrhagic fever. Journal of Clinical Virology, 2007 March; 38(Issue 3): $265-8$.

4. Subhash G, et al. Acute hepatic failure due to dengue: A case report. Cases J, 2008; 1: 204.

5. Subramanian V, Shenoy S, Joseph AJ. Dengue haemorrhagic fever and fulminant hepatic failure, Digestive diseases and sciences, 2005 June; 50(6): p1146-7.

6. SL Seneviratne, GN Malavige, HJ de Silva. Pathogenesis of liver involvement during dengue viral infections (Review). Transactions of the Royal Society of Tropical Medicine and Hygiene 2006; 100: 608-14.

7. Vinodh $\mathrm{BN}$, et al. Dengue fever with acute liver failure. JPostgradMed, 2005 Oct-Dec; 51(4): 322-3.

8. Malavige GN, et al. Patterns of disease in Sri Lankan dengue patients, Arch Dis Child 2006 May; 91(5): 396-400.

9. Luiz JdS, et al. Aminotransferase changes and acute hepatitis in patients with dengue fever: analysis of 1,585 cases, Braz JInfect Dis, 2004 Apr; 8(2): 156-63. 